\title{
IMPROVING IN-SERVICE TEACHER EDUCATORS' COMPETENCES THROUGH DESIGN-BASED RESEARCH
}

\author{
Jari Lavonen \\ Department of Teacher Education, University of Helsinki, Finland • jari.lavonen@helsinki.fi \\ Kalle Juuti \\ Department of Teacher Education, University of Helsinki, Finland \\ Tiina Korhonen \\ Department of Teacher Education, University of Helsinki, Finland \\ Minna Kukkonen \\ Department of Teacher Education, University of Helsinki, Finland \\ Kati Sormunen \\ Department of Teacher Education, University of Helsinki, Finland
}

\begin{abstract}
The aim of the paper is to reflect on collaboration and common actions of in-service teacher educators and researchers. These reflections are made within two design-based research (DBR) projects. The reflection focused on the influence of DBR on participants' competences as inservice teacher educators and their collaboration with researchers. In particular, they learned about the importance of iterations, collaboration and interaction from the point of view of the adoption and usability of new pedagogical innovations. DBR supported researchers, in-service teacher educators and teachers to better share a common world.
\end{abstract}

\section{Introduction}

Science education research has been criticised because the outcomes of the research do not transfer to educational practices or to in-service training or professional development programs (PDPs) organised by trainers or in-service teacher educators (Radford, 1998; Russel \& Martin, 2010). This is because science education researchers and in-service teacher educators who organise PDPs or in-service training do not usually collaborate. Teacher educators focus on the use of new resources or the use of information and communication technology (ICT) too often without any link to current research on their pedagogical use.

This paper introduces an approach that aims to increase the collaboration of in-service teacher educators and science education researchers through common design-based research (DBR) projects. From the point of view of in-service teacher educators, professional development DBR is considered here as a PDP aiming to introduce the inservice teacher educators to new educational or pedagogical knowledge and new methods supportive of the adoption of educational innovations.

In 2011, collaboration between the researchers at the Department of Teacher Education, University of Helsinki (DTEUH), and the in-service teacher educators at the local in-service Teacher Education Centre Innokas (TECI) led to common DBR projects and PDPs that 
focused on the use of ICT in primary science and technology education during the years 2011-2014. The TECI is part of a primary school in the metropolitan area and is responsible for organising PDPs that focus on the use of ICT in teaching and learning for teachers in the city. TECI also promotes and develops technology education through the national Innokas Network.

The research question we will answer through analysing the in-service teacher educators' reflections is: How do teachers/in-service teacher educators experience collaboration and common actions with researchers within two DBR projects?

\section{The design and adoption of educational innovations in the context of DBR}

Educational innovations related to science education need to be adoptable by teachers or by in-service teacher educators in order to have an influence on the development of teaching and the learning of primary science. Moreover, the in-service teacher educators should be able to organise in-service training which supports the adoption of innovations by the school teachers. According to Rogers (2003), an innovation is an object, idea or practice that appears new to an individual or a group, here primary teachers and pupils. An innovation may also be something one has known for some time but has not developed an attitude towards nor adopted or rejected. As totally new ideas are rare, we also consider a modification of an existing idea to be an innovation. For example, a novel use of an ICT in primary science education could be an innovation to a group of persons who have come up with the new use. The versatile use of ICT in primary science teaching and learning is considered here as an educational innovation. Therefore, the innovation includes practical and pedagogical knowledge and skills in the use of ICT in primary science education.

There are two main categories that have an influence on the adoption of the educational innovation at a school: 1) the properties of the innovation and 2) the characteristics of the environment where the innovation is designed and adopted (Fullan, 2007). These two characteristics are also supportive of the design of educational innovations (Müller, Norrie, Hernández, \& Goodson, 2010). Moreover, factors that are supportive for creativity influence the nature and outcomes of the design process of an educational innovation. For example, nonjudgemental, positive feedback and the acceptance of all ideas of group members are important in all creative group processes for generating non-trivial alternatives (Fisher, 2005).

The properties of the innovation in this case are the practical and pedagogical knowledge and skills in the use of ICT in primary science education. The properties of this innovation influence its design adoption by in-service teacher educators and teachers. For example, the innovation will probably not be adopted if its use is too complex for the primary classroom environment or if the use of it is too difficult to learn. The properties of an innovation can be approached from the usability point of view. The usability indicates the extent to which a user can employ it in order to achieve the particular goal which the designers of the tool have set (Nielsen, 1993). Nielsen (1993) suggests that the usability of 
the innovation could be defined by quality metrics such as learnability and the ease of use experienced by users.

The local characteristics, the school site and primary science teaching practices, influence the design and adoption of the innovation. These characteristics include the teachers' pedagogical orientation, their subject matter and pedagogical knowledge and beliefs on teaching and learning as well as the leadership and support available at the school site (Fullan, 2007). Teachers' beliefs are typically connected to the effectiveness, disturbances and control related to the use of the innovation. First, for example, a teacher could wonder whether the new innovation effectively supports the pupils in achieving the aims, whether it disturbs the achievement of important high-level aims or whether the teachers have competence and time to adopt the innovation. This type of thinking refers to the usability of the innovation.

Referring to Rogers (2003), when a teacher is determining whether to accept or reject an innovation, they seek information about the innovation and actively process that information in this research with other teachers in their school. The adoption of an innovation is an individual mental process starting with an initial awareness of the innovation and resulting in the actual adoption of the innovation. The adoption process could be divided into the awareness, interest, evaluation, trial and adoption stages. Consequently, the school structure and operations, leadership, teachers' collaboration, collaboration with families and learning environments are important factors influencing the adoption process. In this study, the aim has been to support adoption through the active collaboration with in-service teacher educators and teachers through common design-based research projects.

A key principle in conducting DBR is that the researchers are not separated from the study subject or in-service teacher educators and teachers at the school site, but instead, work together with and share their world (Juuti \& Lavonen, 2006). The common world could support the researchers, in-service teacher educators and teachers in collaboration to identify the challenges in primary science teaching and learning and, moreover, support them in creating innovative solutions to meet these challenges (Reeves, 2006). DBR methodology is iterative, and research is conducted through the cycles that cover design, implementation and evaluation or piloting. A DBR project produces three types of outcomes: knowledge of teaching and learning, knowledge of a successful iterative design process including collaboration strategies between researchers and teachers and knowledge of successful design solutions and educational innovations (Edelson, 2002). Our interpretation is that innovations should be easy to adopt by the teachers and in-service teacher educators.

Engeström (2011) has criticised the fact that DBR lacks participating teachers' agency. He argues that DBR researchers have ignored the role of teachers in designing processes. Second, Engeström blames DBR for being linear, even though design-based research is said to be iterative. This linearity causes problems for the relationship of researchers and 
teachers. Engeström's (2011) critique could be taken into account through emphasising Dewey's idea of "shared activity" in a DBR project. Dewey uses the notion of shared activity in differentiating the situation where one "does not share in the social use to which his [or her] action is put". In the situation of shared activity, one has "the same interest in its accomplishment which others have. He [or she] would share their ideas and emotion" (Dewey, 1916/1980, MW 9:17).

In DBR, shared activity means that teachers, in-service teacher educators and researchers design, implement and evaluate or pilot educational innovations together. Engaging in shared designing and piloting, obtaining experience in the classroom and anticipating each other's intentions, the researcher and the teacher could come to a stage where they share the same world. A shared world and activity requires communication between teachers and researchers. Biesta and Burbules (2003, p. 41) characterise communication as a process of

the mutual coordination of action, and therefore, it is not a process in which a teacher or teacher educator simply reacts to a researcher's movements, after which the researcher reacts to the teacher's reactions, and so on. Dewey's point means that successful coordination requires that the teacher reacts to what the researcher intends to achieve with his activities, just as the researcher reacts to what the teacher intends to achieve with his activities. Successful coordination requires that the partners in interaction try to anticipate the other's actions.

An important part of the shared activities are common reflection sessions.

We agree with Rodgers (2002), who emphasises, referring to Dewey's work, "that the process of reflection is rigorous and systematic and distinct from other, less structured kinds of thinking" (Rodgers, 2002, p. 863). In a DBR project, it is essential that teachers, in-service teacher educators and researchers together reflect the experiences of the piloted educational innovation. Most probably, participants have different theoretical constructs and views. Therefore, they have different interpretations of what happened in the piloting of the educational innovation. Consequently, reflection on a DBR project is one methodology by which new knowledge concerning teaching and learning is constructed.

\section{The process of the reflection and context of the study}

In this DBR project, reflection has occurred during the in-service teacher educators' and researchers' discussion during the designing and piloting of the educational innovations. As emphasised above, reflection on shared activities is understood as analysis of the design and piloting the educational innovation and, consequently, as data gathering. In order to make the reflection more transparent, we applied written reflection and detail analysis for the more robust outcomes. This procedure ensures that the report is not only a biased story of success, but that critical voices are also acknowledged. 
In-service teacher educators-the last three authors of this paper-wrote a summary reflection, based on their notes, on the nature of the shared activities during the DBR projects in January 2014. We agreed that the in-service teacher educators should focus in their reflection on a) their own learning, b) nature of shared activities and c) the challenges of the DBR projects. The written reflections were analysed following the ideas of inductive content analysis (Elo \& Kyngäs, 2008). The reflections were read several times in order to ensure an accurate interpretation of the in-service teacher educators' expressions. Moreover, the in-service teacher educators read and commented on the interpretations. Finally, we all agreed to the interpretations of the nature of aspects of the DBR projects.

The context of the study was two DBR projects that focused on the development of primary science teaching and learning with ICT. These projects produced three types of outcomes: knowledge of teaching and learning; knowledge of successful design solutions and educational innovations; and knowledge of a successful iterative design process including collaboration strategies between researchers and teachers (Edelson, 2002). First, the DBR projects increased knowledge on personalised science learning in the school and out of school situations (in detail, Sormunen, Lavonen, \& Juuti, 2014) and on pupils' learning of creative problem-solving and inquiry strategies as well as collaboration skills in school-community collaboration (in detail, Kukkonen \& Lavonen, 2014). Second, the DBR projects increased knowledge on the versatile use of ICT tools in personalised primary science learning (in detail, Sormunen, Lavonen, \& Juuti, 2014) and on the versatile use of action team and ICT tools in school-community collaboration (in detail, Kukkonen \& Lavonen, 2014). These two projects are introduced below.

\subsection{Personalising learning through the use of smartphones}

The aim of the first DBR was to develop the use of smartphones in science education in order to personalise learning, especially in the situations where pupils analysed information. For example, the pupils collected and analysed information during the science inquiry activities or from the science-related Internet pages. Moreover, they processed information and communicated the outcomes of the projects with smart phones (Sormunen, Lavonen, \& Juuti, 2014).

Altogether, 49 fifth-grade pupils, two teachers, one in-service teacher educator and two researchers participated in the DBR during the autumn term of 2012. The teachers, pupils, in-service teacher educator and the researchers together designed and implemented the use of smartphones in personalised science learning in the school and out of school situations. The in-service teacher educator wrote the first version of the research plan, which included a theoretical framework of the project. The researchers went through the plan and made comments. The in-service teacher educator organised three iterations altogether and collected raw data. Moreover, she made a preliminary analysis of the data. The analysis and the reliability and validity of the analysis were discussed. 
During the first phase of the DBR project, pupils got to know the smartphones. The experience was used in the second phase, where in-service teacher educators (acting also as class teachers) and pupils planned the use of smartphones. During the third phase of the DBR project, pupils were asked to report their smartphone use during the water-themed science project. The frequencies of pupils' smartphone use reports revealed that they used phones mostly for making notes, revision and information gathering. Comparing teachers' field notes and reviewing the questionnaire data, it was found that teachers' actions strongly affect the use of smartphones in classroom situations.

\subsection{School-kindergarten-library-senior home partnership as an environment for science learning}

In the second DBR project, a new model for school-community collaboration (SCC) emphasising the use of ICT in science learning was developed and researched through an iterative approach where two researchers, an in-service teacher educator, teachers, pupils and out-of-school collaborators were collaborating in real science learning and collaboration situations (Kukkonen \& Lavonen, 2014). The project was planned collaboratively. The in-service teacher educator wrote the first version of the research plan, which included a theoretical framework of the project. The researchers went through the plan and made comments. The in-service teacher educator organised two or three iterations and collected raw data. Moreover, she made a preliminary analysis of the data. The analysis and the reliability and validity of the analysis were discussed.

An action team for partnership (ATP) was created and activated in the frame of Epstein's (2011) theory for school partnership programs. The ATP consisted of two groups, an adults' action team and a pupils' tutor team. The chair for the ATP was the in-service teacher educator, who also belongs to the management team of the school. The ATP was established by inviting a representative of nearby organisations to the school. The organisations were selected based on their location and, furthermore, their positive attitude to collaboration. The ATP was engaged for planning out-of-school learning environments for science learning. The pupils, for example, engaged science-related projects and presented the project outcomes to elderly house people or kindergarten kids.

The data, focusing on partnership and pupil learning in different environments, was gathered through questionnaires, interviews and analysis of artefacts, like journals and videos created by pupils. It was recognised that through the use of ATP and ICT, it is possible to support SCC, which supports pupils' learning of creative problem-solving and science inquiry strategies as well as collaboration skills.

\section{Outcome of the reflection of the DBR projects}

In-service teacher educators described how engagement in DBR increased their competences to act as teachers and in-service teacher educators. One teacher explained, "Through DBR it is possible to contribute to the actions at a school. ... Especially, my 
understanding on the adoption of innovations has increased" (TE 1). DBR has supported all in-service teacher educators to start planning new actions or projects through a literature review and analysis of the needs of parties, then pushing all participants to collaborative and iterative planning, implementation and evaluation of actions: "Before starting a new PDP on the use of videos in a classroom I made some preliminary trials in my own classroom in order to better understand which type of videos and activities are better working in certain situations" (TE 2); "I have emphasised more on collaborative evaluation of planned activities before a new iteration cycle ... you can learn from your mistakes" (TE 3). DBR has offered tools for arguing why a certain way of working is successful and another not. The DBR type of acting has increased in all actions: "I follow DBR type of doing without active recognising of it" (TE 1)"; "Now, I do not give up, I start a new iteration cycle after failure" (TE 2); "All my actions and PDPs are more like iteration cycles" (TE 3).

All three in-service teacher educators emphasised that in the beginning, the researchers were analysing actions in the classroom rather theoretically: "Researchers are far away from school practice" (TE 2). However, after the first cycles, the in-service teacher educators understood the benefit of the DBR collaboration: "As a trainer I have learned how to look [at] situations in the classroom from different theories' point of view" (Teacher 3). Further, collaboration helped researchers to better understand the specific school context.

The in-service teacher educators understood the benefit of the DBR collaboration after a few design cycles: "As a trainer I have learned how to look at situations in the classroom from the point of view of different theories" (TE 3). Collaboration within DBR is interaction, and both parties_are needed and both benefit from the collaboration: "Sometimes theory and practice are far away from each other and, therefore, reciprocal approaches are needed in order to implement innovations to school practice" (TE 3); "In [an] optimal situation the collaboration is sharing of different competencies" (TE 1). We conclude that DBR is supporting researchers and in-service teacher educators sharing the same world.

DBR projects are holistic and long-term projects. DBR needs the commitment of teachers, in-service teacher educators and researchers. All in-service teacher educators see that some resources are needed for teachers to release them from classrooms for meetings and for shared DBR activities. Moreover, headmasters need to be committed and supportive of the projects. In-service teacher educators reflected that novice teachers should become familiar with the basics of iterative school development and research orientation, like DBR: "School development projects are waiting for new teachers after graduation" (TE 2); "DBR orientation should be included to teachers' pre-service training" (TE 1). 


\section{Discussion}

In this paper, we have focused on the third topic in Edelson's (2002) list: successful design solutions, educational innovations (Edelson, 2002) and especially the characteristics of the innovation and school site which are supportive of the design and adoption of educational innovations.

We have analysed the experiences and experienced benefits of the collaboration (shared activities) based on the written reflections of three in-service teacher educators in the context of two DBR projects. The innovations designed in the projects focused on the use of ICT in primary science education. According to the reflections, in-service teacher educators and researchers felt that they were sharing the same world (primary school teaching and learning) while engaging in DBR projects. The in-service teacher educators learned how to organise an iterative DBR project. They learned to plan, implement and evaluate project activities and outcomes. They learned to offer arguments as to why a certain type of activity or scaffolding was needed in order to support pupils' learning. In particular, they adopted the iterative nature of DBR.

In the beginning, researchers and teachers do not necessarily share the same world: the in-service teacher educators think that researchers are looking at classroom situations more theoretically than they do. Therefore, it is important that a DBR project start with cowriting the research plan and common planning sessions. Common planning supports the in-service teacher educators in becoming familiar with the research-based knowledge in the domain of the innovation to be planned. Therefore, teachers' or in-service-teacher educators' beliefs and, moreover, other local characteristics should be taken into account, as Fullan (2007) has emphasised.

In the beginning, the role of iterations was not clear for the in-service teacher education. However, from the point of view of the usability or, more generally, the properties of the innovation, it is important to increase the usability of the innovation (Nielsen, 1993). Through the iteration cycles, the properties of the innovation could be developed in order to support the teacher in employing the innovation in a productive way. Therefore, a DBR project has offered supports for designing educational innovations which are easy to adopt by in-service teacher educators working with in-service teachers. Moreover, other characteristics of the usability, like the learnability of the innovation, could be developed. A DBR approach also takes into account the local characteristics of the site, because all planning and piloting are organised at the school site. Thus, researchers have possibilities to better understand the actual primary school teaching and learning environments. Further, a DBR project modifies the educational innovation to a form which is supportive for adoption. The iterative nature, sharing of a common world and researchers' and inservice teacher educators' common reflection situations take into account the properties of the innovation and the local characteristics which Fullan (2007) argues to be important for the adoption of the innovation. 
Several iteration cycles are needed in order to have opportunities for sharing observations and interpretations of them. This supports the conceptualisation of the observed phenomena in the domain of the innovation and, moreover, supports the inservice teacher educators in the next phase, supporting other teachers to adopt the new innovation. All participants - researchers, in-service teacher educators, ordinary teachers, and even pupils - should have an active role during the planning, designing and implementation phases and, moreover, in the reflection session, where the outcomes of the cycles are evaluated. These characteristics would emphasise teachers' and in-service teacher educators' agency in a DBR project, which Engeström (2011) posited as absent in DBR.

Teachers emphasise in their reflections several topics which are supportive of interaction between in-service teacher educators and between them and researchers (Rogers, 2003). In particular, iteration cycles are supportive for several discussions on the innovation. The different theoretical points of view support the teachers in analysing the innovation in a versatile way and in seeking information about the innovation and actively processing that information. Moreover, the in-service teacher educators have understood that the adoption takes time and is a process, starting with an initial awareness and resulting in the adoption of the innovation. Therefore, the in-service teacher educators have learned that it is important to support adoption through the active collaboration between in-service teacher educators and teachers.

\section{References}

Biesta, G. J. J., \& Burbules, N. C. (2003). Pragmatism and educational research. Lanham, MD: Rowman \& Littlefield Publishers.

Dewey, J. (1916/1980). Democracy and education. In A. Boydston (Ed.), The middle works 18991924 (Vol. 9). Carbondale: Southern Illinois University Press.

Edelson, D. C. (2002). Design research: What we learn when we engage in design. The Journal of the Learning Sciences, 11(1), 105-121.

Elo, S., \& Kyngäs, H. (2008). The qualitative content analysis process. Journal of Advanced Nursing, 62(1), 107-115.

Engeström, Y. (2011). From design experiments to formative interventions. Theory \& Psychology, 21(5), 598-628.

Epstein, J. L. (2011). School, family, and community partnerships (2nd ed.). Westview Press.

Fisher, R. (2005). Teaching children to think (2nd ed.). Cheltenham: Nelson Thornes.

Fullan, M. (2007). The new meaning of educational change (4th ed.). New York and London: Teachers College Press.

Juuti, K., \& Lavonen, J. (2006). Design-based research in science education: One step towards methodology. Nordic Studies in Science Education, 4, 54-68

Kukkonen, M., \& Lavonen, J. (2014). Crossing classroom boundaries through the use of collaboration-supporting ICT: A case study on school-kindergarten-library-senior home partnership. In H. Niemi, J. Multisilta, \& E. Löfström (Eds.), Crossing boundaries for learning through technology and human efforts (pp. 67-90). Helsinki: CICERO Learning Network, University of Helsinki.

Müller, J., Norrie, C., Hernández, F., \& Goodson, I. (2010). Restructuring teachers' work-lives and knowledge in England and Spain. Compare, 4O(3), 265-277. 
Nielsen, J. (1993). Usability engineering. Boston (MS.): Academic Press.

Radford, D. L. (1998). Transferring theory into practice: A model for professional development for science education reform. Journal of Research in Science Teaching, 35(1), 73-88.

Reeves, T. C. (2006). Design research from technology perspective. In J. van den Akker, K. Gravemeijer, S. Mc Kenney, \& N. Nieveen (Eds.), Educational design research. London: Routledge.

Rodgers, C. (2002). Defining reflection: Another look at John Dewey and reflective thinking. Teachers College Record, 104(4), 842-866.

Rogers, E. M. (2003). Diffusion of innovations (5th ed.). New York: Free Press.

Russel, T., \& Martin A. K. (2010). Learning to teach science. In S. K. Abell \& N. G. Lederman (Eds.), Handbook of research on science education (pp. 1174-1175). New York, NY: Routledge.

Sormunen, K., Lavonen, J., \& Juuti, K. (2014). Crossing classroom boundaries in science teaching and learning through the use of smartphones. In H. Niemi, J. Multisilta, \& E. Löfström (Eds.), Crossing boundaries for learning - through technology and human efforts (pp. 91-111).

Helsinki: CICERO Learning Network, University of Helsinki. 